\title{
Variation in treatment of acute childhood wheeze in emergency departments of the United Kingdom and Ireland: an international survey of clinician practice
}

\author{
Mark D Lyttle, ${ }^{1,2}$ Ronan O'Sullivan, ${ }^{3,4,5}$ Iolo Doull, ${ }^{6}$ Stuart Hartshorn, ${ }^{7}$ Ian Morris, ${ }^{8}$ \\ Colin V E Powell, ${ }^{9,10}$ on behalf of PERUKI
}

\begin{abstract}
${ }^{1}$ Academic Department of Emergency Care, University of the West of England, Bristol, UK

${ }^{2}$ Emergency Department, Bristol Royal Hospital for Children, Bristol, UK

${ }^{3}$ Department of Emergency Medicine, Cork University

Hospital, Cork, Ireland

${ }^{4}$ School of Medicine, University

College Cork, Cork, Ireland

${ }^{5}$ Paediatric Emergency

Research Unit (PERU), National

Children's Research Centre,

Dublin 12, Ireland

${ }^{6}$ Department of Paediatric Respiratory Medicine and

Specialist Cystic Fibrosis Centre, Children's Hospital for Wales,

Cardiff, UK

${ }^{7}$ Birmingham Children's

Hospital NHS Foundation Trust, Birmingham, UK

${ }^{8}$ Children's Hospital for Wales, Wales Deanery, Cardiff, UK ${ }^{9}$ Department of Child Health, Children's Hospital for Wales, Cardiff, UK

${ }^{10}$ Institute of Molecular and Experimental Medicine, Cardiff University School of Medicine, Cardiff, UK
\end{abstract}

\section{Correspondence to} Dr Mark D Lyttle, Emergency Department, Bristol Royal Hospital for Children, Bristol BS2 8BJ, UK; Mark.lyttle@uhbristol.nhs.uk

Received 12 April 2014 Revised 2 July 2014 Accepted 4 August 2014 Published Online First 25 August 2014

\begin{abstract}
Objective National clinical guidelines for childhood wheeze exist, yet despite being one of the most common reasons for childhood emergency department (ED) attendance, significant variation in practice occurs in other settings. We, therefore, evaluated practice variations of ED clinicians in the UK and Ireland.

Design Two-stage survey undertaken in March 2013.

Stage one examined department practice and stage two assessed ED consultant practice in acute childhood wheeze. Questions interrogated pharmacological and other management strategies, including inhaled and intravenous therapies.
\end{abstract}

Setting and participants Member departments of Paediatric Emergency Research in the United Kingdom and Ireland and ED consultants treating children with acute wheeze.

Results 30 EDs and 183 (81\%) clinicians responded. $29(97 \%)$ EDs had wheeze guidelines and 12 (40\%) had care pathways. Variation existed between clinicians in dose, timing and frequency of inhaled bronchodilators across severities. When escalating to intravenous bronchodilators, 99 (54\%) preferred salbutamol first line, $52(28 \%)$ magnesium sulfate $\left(\mathrm{MgSO}_{4}\right)$ and $27(15 \%)$ aminophylline. 87 (48\%) administered intravenous bronchodilators sequentially and 30 (16\%) concurrently, with others basing approach on case severity. 146 $(80 \%)$ continued inhaled therapy after commencing intravenous bronchodilators. Of 170 who used intravenous salbutamol, $146(86 \%)$ gave rapid boluses, $21(12 \%)$ a longer loading dose and $164(97 \%)$ an ongoing infusion, each with a range of doses and durations. Of 173 who used intravenous $\mathrm{MgSO}_{4}$, all used a bolus only. 41 (24\%) used non-invasive ventilation.

Conclusions Significant variation in ED consultant management of childhood wheeze exists despite the presence of national guidance. This reflects the lack of evidence in key areas of childhood wheeze and emphasises the need for further robust multicentre research studies.

\section{INTRODUCTION}

Asthma is the most common chronic medical condition of childhood, with rates in the UK and Ireland among the highest in the world. ${ }^{1-4}$ It remains a significant cause of mortality and morbidity and the National Health Service spends $£ 1$ billion on asthma annually, with costs higher in children than adults. ${ }^{4}$ In the context of increasing childhood admission rates, asthma accounts for $64 \%-73 \%$ of those for chronic conditions and

\section{What is already known on this topic}

- Childhood asthma is the most common chronic medical condition of childhood and one of the most common reasons for attendance to urgent and emergency care and admission to hospital.

- National guidance exists for the management of acute childhood wheeze, though there is a paucity of evidence in some areas of practice.

- Variation in treatment and investigation of acute childhood wheeze has been demonstrated in other settings and variation in hospitalisation rates across primary care trusts exists in our setting.

\section{What this study adds}

- Across the UK and Ireland, variation exists in the treatment of acute severe childhood wheeze, especially in inhaled and intravenous bronchodilator selection, dosage and frequency.

- We have identified key areas of variation, which require further exploration to determine their impact at the patient interface.

- There is an urgent need for multicentre studies to address the paucity of evidence for management of severe childhood wheeze to inform recommendations.

wheezing is one of the most common reasons for hospitalisation overall. ${ }^{5}{ }^{6}$ While there is variation in severity and pathophysiology with overlap between asthma and viral induced wheeze (VIW), wheezing is consistently identified as a leading presentation to emergency departments (EDs) in other healthcare settings. 78

National guidelines and quality standards exist for the management of wheezing. ${ }^{9-11}$ Many recommendations derive from high quality studies, but some are based on lesser evidence or expert consensus. Paucity of evidence results in guidance which cannot provide detail in some areas, potentially leading to individual interpretation and practice variation as in other systems. ${ }^{12} 13$ This may contribute to differences in admission rates, bed days and length of stay across English primary care trusts. $^{5}$ 
Practice variation may result in poorer health outcomes, unnecessary medical treatments and increased strain on the healthcare system. ${ }^{14}$ Determining baseline practice and identifying variation in wheeze management will highlight areas where implementing existing guidance could improve care and identify key areas for future research.

We aimed to determine whether variation exists in the clinical care of acute severe childhood wheeze across the UK and Ireland through a survey completed by senior clinical decision makers. The survey examined differences in approach to severe wheeze and the use of inhaled, oral and intravenous therapies.

\section{METHODS}

Paediatric Emergency Research in the United Kingdom and Ireland (PERUKI) ${ }^{15}$ sites participated in a two-stage survey via Bristol Online Surveys. Stage one assessed department practice, including information on clinical practice guidelines (CPG), care pathways (CP) and site-specific features including admission location. In stage two, consultants provided information on personal practice including assessment and management, inhaled and intravenous bronchodilators, escalation of care and alternative treatments. Returns were collated using Microsoft Excel 2010 and descriptive analysis was undertaken. PERUKI is a research collaborative of individuals and departments from England, Ireland, Northern Ireland, Scotland and Wales which comprises paediatric-specific and mixed adult and paediatric EDs that represent secondary and tertiary care. ${ }^{15}$ Further information is available online (http://www.peruki.org).

\section{ETHICS}

This was confirmed as service evaluation by the research design service at the study lead site.

\section{RESULTS}

Thirty centres participated and 183/226 (81\%) consultants completed the survey. Responses were obtained from a range of regions, department types and specialties (table 1). A total of 29 (96.7\%) departments had a CPG and 12 (40\%) had a CP. All CPGs reflected national guidance with variations mainly in drug and dose selection. In all, 20 (66.7\%) described specific admission locations for children receiving intravenous therapy. In 15 (75\%), this included a paediatric high dependency unit and in 7 (35\%), an inpatient ward. In 5 (25\%), this included paediatric intensive care (PIC) with two mandating PIC if on intravenous salbutamol.

\section{Assessment and general approach}

Most clinicians $(113,61.7 \%)$ adopt the same approach in all children 1 year and older. Overall, 70 (38.3\%) modify clinical care depending on whether the diagnosis is asthma or VIW, with several stating they are less likely to prescribe steroids for VIW. Minor variations exist in intensity of inhaled bronchodilators and timing of intravenous therapy. Most clinicians use the British Thoracic Society/ Scottish Intercollegiate Guidelines Network (BTS/SIGN) criteria $^{9}$ to assess severity, the most common being 'inability to complete sentences, too breathless to talk/feed' $(180,98.4 \%)$ and hypoxia $(177,96.7 \%) ; 106$ $(57.9 \%)$ class episodes as severe if 'more than one (but not necessarily all) are present'. A total of 156 (85.2\%) had a peak expiratory flow rate (PEFR) meter, but only $22(14.1 \%)$ always use this to assess severity. Those who 'sometimes' use PEFR meters do so in 'older children' or those with known PEFR (table 2).
Table 1 Respondent characteristics

\begin{tabular}{|c|c|c|c|}
\hline & $\begin{array}{l}\text { Number of } \\
\text { respondents }\end{array}$ & $\begin{array}{l}\text { Per cent of } \\
\text { respondents }\end{array}$ & $\begin{array}{l}\text { Number } \\
\text { of sites }\end{array}$ \\
\hline \multicolumn{4}{|l|}{ Country } \\
\hline England & 134 & 73.2 & 20 \\
\hline Scotland & 21 & 11.5 & 4 \\
\hline Ireland & 18 & 9.8 & 4 \\
\hline Wales & 7 & 3.8 & 1 \\
\hline $\mathrm{N}$ Ireland & 3 & 1.6 & 1 \\
\hline \multicolumn{4}{|l|}{ Department } \\
\hline Generic emergency department & 73 & 39.9 & \\
\hline General paediatrics/child health* & 72 & 39.3 & \\
\hline Children's emergency department & 38 & 20.8 & \\
\hline \multicolumn{4}{|l|}{ Specialty } \\
\hline General paediatrics & 63 & 34.4 & \\
\hline Paediatric emergency medicine (EM) & 60 & 32.8 & \\
\hline EM & 28 & 15.3 & \\
\hline $\begin{array}{l}\text { EM with paediatric subspecialty } \\
\text { interest }\end{array}$ & 18 & 9.8 & \\
\hline Consultant in respiratory paediatrics & 7 & 3.8 & \\
\hline Othert & 7 & 3.8 & \\
\hline
\end{tabular}

\section{Inhaled bronchodilators}

All clinicians use inhaled salbutamol. A total of 117 (63.9\%) use nebulisers in the presence of hypoxia and metered dose inhalers (MDIs) in its absence, most commonly giving three doses initially followed by reassessment. In all, 173 (94.6\%) use ipratropium bromide at least sometimes: 75 (43.4\%) do so immediately and $67(38.7 \%)$ if no response to the first salbutamol dose. Dosages of both vary in general increasing with age, though in some cases the same dose is given across all age ranges, most noticeably in salbutamol MDI (table 3).

Table 2 Assessment of acute wheeze

\begin{tabular}{|c|c|c|}
\hline & Number & Per cent \\
\hline \multicolumn{3}{|c|}{ Do you assess and manage asthma and acute viral induced wheeze differently? } \\
\hline No & 113 & 61.7 \\
\hline Yes & 70 & 38.3 \\
\hline \multicolumn{3}{|c|}{ Which of the following do you use to classify episode as severe?* } \\
\hline Can't complete sentences/too breathless to talk or feed & 180 & 98.4 \\
\hline Low oxygen saturations & 177 & 96.7 \\
\hline High respiratory rate & 152 & 83.1 \\
\hline High pulse rate & 131 & 71.6 \\
\hline \multicolumn{3}{|l|}{ Do you class the episode as severe if? } \\
\hline More than one, not necessarily all are present & 106 & 57.9 \\
\hline Any are present in isolation & 72 & 39.3 \\
\hline Only if all are present & 5 & 2.7 \\
\hline \multicolumn{3}{|l|}{ Does your department have a peak expiratory flow rate meter? } \\
\hline Yes & 156 & 85.2 \\
\hline No & 16 & 8.7 \\
\hline Don't know & 11 & 6.0 \\
\hline \multicolumn{3}{|l|}{ If you have one, do you use it to determine severity? } \\
\hline Sometimes & 90 & 57.7 \\
\hline No & 44 & 28.2 \\
\hline Yes & 22 & 14.1 \\
\hline
\end{tabular}

*Values given in survey as per British Thoracic Society guidance. 
Table 3 Dosage regimes of inhaled salbutamol and ipratropium

\begin{tabular}{|c|c|c|c|c|c|}
\hline & $\begin{array}{l}<2 \text { Years } \\
\mathrm{n}(\%)\end{array}$ & $\begin{array}{l}2-<5 \text { Years } \\
n(\%)\end{array}$ & $\begin{array}{l}5-<12 \text { Years } \\
\mathrm{n}(\%)\end{array}$ & $\begin{array}{l}\geq 12 \text { Years } \\
\mathrm{n}(\%)\end{array}$ & $\begin{array}{l}\text { Same } \\
\text { for all } \\
\mathrm{n}(\%)\end{array}$ \\
\hline \multicolumn{6}{|c|}{ Salbutamol MDI (number of puffs) } \\
\hline 2 & $1(0.6)$ & $0(0)$ & $0(0)$ & $0(0)$ & \multirow[t]{8}{*}{$112(60.2)$} \\
\hline 4 & $2(1.2)$ & $2(1.2)$ & $0(0)$ & $0(0)$ & \\
\hline 5 & $12(7.4)$ & $9(5.4)$ & $1(0.6)$ & $1(0.6)$ & \\
\hline 6 & $20(12.3)$ & $16(9.6)$ & $6(3.6)$ & $2(1.2)$ & \\
\hline 8 & $2(1.2)$ & $4(2.4)$ & $0(0)$ & $0(0)$ & \\
\hline 10 & $112(69.1)$ & $125(75.3)$ & $148(89.2)$ & $146(89.6)$ & \\
\hline 12 & $1(0.6)$ & $1(0.6)$ & $3(1.8)$ & $6(3.7)$ & \\
\hline Other & $12(7.4)$ & $9(5.4)$ & $8(4.8)$ & $8(4.9)$ & \\
\hline \multicolumn{6}{|c|}{ Salbutamol nebuliser (dose in milligrams) } \\
\hline 1.25 & $3(1.8)$ & $0(0)$ & $0(0)$ & $0(0)$ & \multirow[t]{4}{*}{$16(32.3)$} \\
\hline 2.5 & $152(90.5)$ & $146(84.4)$ & $7(4)$ & $2(1.2)$ & \\
\hline 5 & $7(4.2)$ & 20 (11.6) & $155(89.1)$ & $166(96)$ & \\
\hline Other & $6(3.6)$ & $7(4)$ & $12(6.9)$ & $5(2.9)$ & \\
\hline \multicolumn{6}{|c|}{ Ipratropium MDI (number of puffs) } \\
\hline 1 & $3(5.7)$ & $3(5.8)$ & $0(0)$ & $0(0)$ & \multirow[t]{8}{*}{$34(19.5)$} \\
\hline 2 & $24(45.2)$ & $22(42.3)$ & 17 (34) & $16(32)$ & \\
\hline 4 & $14(26.4)$ & $15(28.8)$ & $13(26)$ & $12(24)$ & \\
\hline 5 & $2(3.8)$ & $2(3.8)$ & $1(2)$ & $1(2)$ & \\
\hline 6 & $3(5.7)$ & $5(9.6)$ & $5(10)$ & $7(14)$ & \\
\hline 8 & $0(0)$ & $0(0)$ & 7 (14) & $8(16)$ & \\
\hline 10 & $1(1.9)$ & 1 (1.9) & $2(4)$ & $2(4)$ & \\
\hline Other & $6(11.3)$ & $4(7.7)$ & $5(10)$ & $4(8)$ & \\
\hline \multicolumn{6}{|c|}{ Ipratropium nebuliser (dose in micrograms) } \\
\hline 62.5 & $12(7.7)$ & $1(0.6)$ & $0(0)$ & $0(0)$ & \multirow[t]{5}{*}{$27(15.5)$} \\
\hline 125 & 58 (37.2) & $42(26.9)$ & $5(3.2)$ & $2(1.3)$ & \\
\hline 250 & $73(46.8)$ & $104(66.7)$ & 97 (61.8) & 65 (41.4) & \\
\hline 500 & $6(3.8)$ & $2(1.2)$ & 49 (31.2) & 87 (55.4) & \\
\hline Other & $7(4.5)$ & $7(4.5)$ & $6(3.8)$ & $3(1.9)$ & \\
\hline
\end{tabular}

\section{Steroids}

All use prednisolone $1-2 \mathrm{mg} / \mathrm{kg}$ as the oral steroid of choice; none use dexamethasone. A total of 181 (98.9\%) use hydrocortisone as the intravenous steroid of choice. In all, 73 (39.8\%) use intravenous steroids 'only if oral is not tolerated', 46 (25.1\%) use intravenous 'when giving intravenous bronchodilators regardless of whether oral steroid has been given' and 27 $(14.8 \%)$ use intravenous 'when giving intravenous bronchodilators if oral steroid has not been given'. None use inhaled steroids acutely.

\section{Escalating to intravenous therapy}

In all, 170 (92.9\%) escalate for deteriorating severe wheeze, $166(90.7 \%)$ for life-threatening wheeze and 141 (77\%) if there is no response to inhaled bronchodilators; $167(91.8 \%)$ require more than one criterion and $172(93.9 \%)$ use these on a case-by-case basis. Low numbers use set criteria such as time since starting or total accrued dose of inhaled therapy. In all, 99 (54.1\%) use salbutamol as first-line intravenous therapy, 52 (28.4\%) magnesium sulfate and 27 (14.8\%) aminophylline; 87 $(47.5 \%)$ give these sequentially depending on response and 30 (16.4\%) give them concurrently. Overall, 146 (79.8\%) continue inhaled bronchodilators while on intravenous therapy.
Table 4 Intravenous salbutamol regimes

\begin{tabular}{|c|c|c|}
\hline & Number & Per cent \\
\hline \multicolumn{3}{|l|}{ Which regimen do you use for intravenous salbutamol } \\
\hline Bolus then continuous infusion & 126 & 68.3 \\
\hline Loading dose then continuous infusion & 12 & 6.6 \\
\hline Continuous infusion & 12 & 7.1 \\
\hline Bolus only & 5 & 2.7 \\
\hline Bolus, then loading dose, then continuous infusion & 7 & 3.8 \\
\hline Don't use & 13 & 7.1 \\
\hline Other & 8 & 4.4 \\
\hline \multicolumn{3}{|l|}{ Do you use a bolus dose? } \\
\hline Yes & 146 & 85.9 \\
\hline No & 24 & 14.1 \\
\hline \multicolumn{3}{|l|}{ What dose do you give as a bolus? } \\
\hline $15 \mu \mathrm{g} / \mathrm{kg}$ & 89 & 61 \\
\hline $5 \mu \mathrm{g} / \mathrm{kg}$ if $<2$ year, $15 \mu \mathrm{g} / \mathrm{kg}$ if $\geq 2$ year & 54 & 37 \\
\hline $5-10 \mu \mathrm{g} / \mathrm{kg}$ & 1 & 0.7 \\
\hline $5 \mu \mathrm{g} / \mathrm{kg}$ & 2 & 1.4 \\
\hline \multicolumn{3}{|l|}{ Duration of bolus dose (min) } \\
\hline 10 & 68 & 46.6 \\
\hline 5 & 38 & 26 \\
\hline 15 & 15 & 10.3 \\
\hline 20 & 12 & 8.2 \\
\hline $5-10$ & 9 & 6.2 \\
\hline $5-15$ & 2 & 1.4 \\
\hline 30 & 2 & 1.4 \\
\hline \multicolumn{3}{|l|}{ Do you give a loading dose } \\
\hline No & 149 & 87.6 \\
\hline Yes & 21 & 12.4 \\
\hline \multicolumn{3}{|l|}{ What loading dose do you use? } \\
\hline $5 \mu \mathrm{g} / \mathrm{kg} / \mathrm{min}$ & 21 & 100 \\
\hline \multicolumn{3}{|l|}{ What duration do you load over? (min) } \\
\hline 60 & 16 & 76.2 \\
\hline $60-120$ & 5 & 23.8 \\
\hline \multicolumn{3}{|l|}{ Do you use a continuous infusion? } \\
\hline Yes & 164 & 96.5 \\
\hline No & 6 & 3.5 \\
\hline \multicolumn{3}{|l|}{ What dose regimen do you use $(\mu \mathrm{g} / \mathrm{kg} / \mathrm{min})$} \\
\hline $1-5$ & 76 & 46.3 \\
\hline $1-2$ & 52 & 31.7 \\
\hline 1 & 12 & 7.3 \\
\hline $0.5-6$ & 9 & 5.5 \\
\hline $2-5$ & 9 & 5.5 \\
\hline $1-3$ & 2 & 1.2 \\
\hline $0.5-1$ & 1 & 0.6 \\
\hline $0.6-1$ & 1 & 0.6 \\
\hline $1-6$ & 1 & 0.6 \\
\hline 5 & 1 & 0.6 \\
\hline
\end{tabular}

\section{Intravenous bronchodilators}

A total of 170 (92.9\%) use intravenous salbutamol, though in a range of strategies and doses. For the purposes of this study, a continuous infusion was defined as a 'weight based rate (micrograms $/ \mathrm{kg} / \mathrm{min}$ ) with no fixed endpoint'; a loading dose as a 'weight based rate (micrograms $/ \mathrm{kg} / \mathrm{min}$ ) given for a set period of time' and a bolus as a 'weight based dose (micrograms/kg)'. Five general strategies are employed, the most common being 'bolus and continuous infusion'. For boluses, four doses and seven durations were described. There were 10 different continuous infusion rates with over 10-fold variation between the lowest and highest (table 4). 
Overall, 142 (77.6\%) use aminophylline, with 127 (89.4\%) giving 'bolus and infusion'; $132(93 \%)$ give a bolus, of which $120(91 \%)$ give $5 \mathrm{mg} / \mathrm{kg}, 5(3.8 \%)$ give each of 6 or $7.5 \mathrm{mg} / \mathrm{kg}$ and one $10 \mathrm{mg} / \mathrm{kg}$. In all, 120 (91\%) give the bolus over 20$30 \mathrm{~min}$. Nine continuous infusion rates were described, all at $1 \mathrm{mg} / \mathrm{kg} / \mathrm{h}$ or less, with $1 \mathrm{mg} / \mathrm{kg} / \mathrm{h}$ being the most common $(68.6 \%)$.

In all, 173 (94.5\%) use magnesium sulfate; all used a bolus with no subsequent infusion and $141(81.5 \%)$ give $40-50 \mathrm{mg} / \mathrm{kg}$ over 20-30 min.

\section{Other therapies}

A total of $116(62 \%)$ stated that more invasive therapy including intubation was outside their scope of practice. Of 67 (36.7\%) who intubate, 62 (93\%) use ketamine for induction of anaesthesia. Overall, 41 (24\%) use non-invasive ventilation and 4 (2\%) use heliox. Other therapies included adrenaline (4, 2.2\%), high flow oxygen $(4,2.2 \%)$, calm environment $(3,1.6 \%)$, DNAse $(2,1.1 \%)$, physiotherapy $(1,0.5 \%)$, total histamine blockade $(1,0.5 \%)$, intravenous ketamine $(1,0.5 \%)$ or monteleukast $(1,0.5 \%)$.

\section{DISCUSSION}

In establishing baseline practice across a range of sites and clinicians in the UK and Ireland, we have demonstrated variation in management of acute severe childhood wheeze. This exists in assessment and treatment, especially inhaled and intravenous bronchodilator selection, dosage and frequency, reflecting the paucity of evidence underpinning recommendations.

CPGs such as BTS/SIGN national guidance ${ }^{9}$ assist clinicians in healthcare decisions and are underpinned by best available evidence. CPs translate and clarify CPGs, including timing and dosage of treatment, and as a result they streamline management plans across handovers, reduce variability and errors in care, prompt use of best evidence, improve education, and potentially shorten length of stay. ${ }^{14} 16$ The CPGs we collected were based on BTS/SIGN guidance ${ }^{9}$ varying mainly in bronchodilator selection/dosage and system processes. Overall, $40 \%$ had a wheeze $\mathrm{CP}$, representing an opportunity to share best practice. In future, CPs should capitalise on available technology and be used across all healthcare settings, including primary care, EDs and inpatient settings.

Variations in inhaled therapy included delivery method, drug selection, dosage and frequency. Most used MDIs in children with no oxygen requirement, though one-fifth always used nebulisers. Most gave the BTS/SIGN salbutamol MDI dose, though some tended towards lower doses in younger children. Ipratropium bromide use is more varied as in other healthcare systems, perhaps due to conflicting literature. ${ }^{13}$ However, in a recent systematic review, children treated with ipratropium bromide and salbutamol compared with salbutamol alone have lower rates of hospital admission, nausea and tremor and greater improvement in lung function. ${ }^{17}$

More than half used salbutamol as the first-line intravenous agent, while fewer preferred magnesium sulfate or aminophylline, suggesting equipoise regarding which is most efficacious. To investigate this, we asked participants whether they would enrol patients to a randomised controlled trial allocating salbutamol, aminophylline or magnesium sulfate as the first-line intravenous agent, to which 148 (80.9\%) responded positively.

Uncertainty exists regarding the optimal dose and administration strategy, especially for salbutamol, contributed to by numerous dosage terminologies. We defined these terms through reference to available CPGs, though some would reserve the term 'loading' for a dose which is followed by continuous infusion and 'bolus' for a dose not followed by an infusion. There is threefold and 10-fold variation in bolus doses and continuous infusion rates, respectively, and infrequent usage of loading doses, reflecting the paucity of evidence on the pharmacokinetics of intravenous salbutamol. ${ }^{18}$ BTS/SIGN guidelines suggest a bolus of $15 \mu \mathrm{g} / \mathrm{kg}$ over $10 \mathrm{~min}$, followed by an infusion of $1-5 \mu \mathrm{g} / \mathrm{kg} / \mathrm{min}$ if required with no loading dose described. Key studies suggest a bolus of $15 \mu \mathrm{g} / \mathrm{kg}^{19}$ or a loading dose of $5 \mu \mathrm{g} / \mathrm{kg} / \mathrm{min}$ for $1 \mathrm{~h}^{20}{ }^{21}$ Respectively, these are equivalent to $1.5 \mu \mathrm{g} / \mathrm{kg} / \mathrm{min}^{19}$ (the lower end of guidance) or a total dose of $300 \mu \mathrm{g} / \mathrm{kg}^{20} 21$ (20 times that suggested by guidance). In further analysing the dose given prior to any continuous infusion, there is a 60 -fold variation between a single $5 \mu \mathrm{g} / \mathrm{kg}$ dose and a dose of $5 \mu \mathrm{g} / \mathrm{kg} / \mathrm{min}$ given for $1 \mathrm{~h}$.

Knowledge translation may take several years, ${ }^{14}$ though recent evidence may result in practice change. For example, a recent trial of inhaled magnesium sulfate reported improvement in a subset of children ${ }^{22}$ and oral dexamethasone may provide an alternative to prednisolone, appearing at least as effective and more palatable. ${ }^{24-29}$

Variation may be reduced by dissemination of research and sharing of best practice across networks. There is, therefore, a need for rigorously conducted multicentre research on topics including development of a minimum data set, identification of wheeze phenotypes and the optimal strategies for treatment of acute severe wheeze. These include studies on inhaled bronchodilators in the first hour, intravenous bronchodilator selection, dexamethasone compared with prednisolone and other therapies such as inhaled steroids. Several of these were identified as important to clinicians through a research prioritisation exercise performed by PERUKI. ${ }^{30}$ Only in answering these questions can variation be reduced and clinical care improved in this important, common and potentially life-threatening condition.

\section{LIMITATIONS}

This study relied on accurate reporting by individual clinicians. However, our approach allowed us to analyse practice of a large number of consultant clinicians from a number of regions and our high response rate means we are confident we have identified key variations. We did not focus on a wider range of practitioners, but this is reasonable given many EDs have a consultant-delivered service. We have identified variation in practice, but cannot determine best practice. However, our methods allow assessment of variation, outline areas for implementation and highlight areas in which there is a paucity of evidence. We assessed a range of practice points in a short time and identified areas for investigation, the first of which has been completed. $^{31}$

\section{CONCLUSIONS}

Variation exists in the assessment and treatment of acute severe childhood wheeze across the UK and Ireland. Key areas include inhaled and intravenous bronchodilator selection, dosage and frequency, reflecting the paucity of evidence. We have identified opportunities for best practice dissemination and highlighted clinical questions which must be answered by robust multicentre research to improve clinical care of this common childhood condition.

Collaborators The following acted as site lead investigators for this study and were responsible for data collection, sharing guidelines and department procedures, and ensuring completion of surveys: J Barling, University Hospital Southampton NHS Foundation Trust; J Bayreuther, Lewisham and Greenwich NHS Trust, London; C Bevan, Royal Alexandra Children's Hospital, Brighton; T Bolger, Tallaght Hospital, Dublin; D Burke, Sheffield Children's NHS Foundation Trust; V Choudhery, Royal 
Hospital for Sick Children, Glasgow; J Criddle, Evelina Hospital, London; E Dalzell, Royal Belfast Hospital for Sick Children, Belfast; F Davies, University Hospitals Leicester NHS Trust; C Dieppe, Nottingham Children's Hospital, Nottingham; I Grice, Alder Hey Hospital, Liverpool; G Hadley, St Mary's Hospital, London; S Hartshorn, Birmingham Children's Hospital, Birmingham; A Kidd, Royal Hospital for Sick Children, Edinburgh; I Maconochie, St Mary's Hospital, London; R McNamara, Temple Street Children's University Hospital, Dublin; M Mitchelson, Royal Aberdeen Children's Hospital, Aberdeen; N Mullen, City Hospitals Sunderland Foundation Trust; J Mulligan, University Hospital Crosshouse, Kilmarnock; R O'Sullivan, Cork University Hospital, Cork; R O'Sullivan, Our Lady's Children's Hospital, Crumlin; A Parikh, Royal London Hospital, Barts Health NHS Trust; K Potier, Royal Manchester Children's Hospital, Manchester; S Potter, Bristol Royal Hospital for Children, Bristol; Z Roberts, Children's Hospital for Wales, Cardiff; G Robinson, Royal Derby Hospital, Derby; J Ross, Chelsea and Westminster Healthcare NHS Foundation Trust, London; A Rowland, North Manchester General Hospital, Manchester; JE Smith, Derriford Hospital, Plymouth; S Wong, Royal Free London NHS Foundation Trust, London; P Younge, North Bristol Trust, Bristol.

Contributors MDL and CVEP conceived and designed the study, developed the survey, collated and analysed the data and drafted the article. ROS, SH, ID and IM contributed to the development of the survey and data analysis, and participated in drafting the final article.

Competing interests None.

Provenance and peer review Not commissioned; externally peer reviewed.

Data sharing statement All data collected are presented within this article. Should readers wish further detail on any results, this can be obtained by contacting the corresponding author.

\section{REFERENCES}

1 Asthma UK: facts and FAQs. http://www.asthma.org.uk/asthma-facts-and-statistics (accessed 2 Mar 2014).

2 Facts \& Figures on Asthma. http://www.asthma.ie/node/164 (accessed 2 Mar 2014).

3 Manning PJ, Goodman P, O'Sullivan A, et al. Rising prevalence of asthma but declining wheeze in teenagers (1995-2003): ISAAC protocol. Ir Med J 2007:100:614-15.

4 Paton J. Asthma: standards of care. Arch Dis Child 2013;98:928-9.

5 Child and Maternal Health Intelligence Network, Asthma Disease Management Information Toolkit. http://atlas.chimat.org.uk/IAS/dmit (accessed 2 Mar 2014).

6 Gill PJ, Goldacre MJ, Mant D, et al. Increase in emergency admissions to hospital for children aged under 15 in England, 1999-2010: national database analysis. Arch Dis Child 2013:98:328-34.

7 Alpern ER, Stanley RM, Gorelick MH, et al.; for the Pediatric Emergency Care Applied Research Network. Epidemiology of a pediatric emergency medicine research network: the PECARN Core Data Project. Pediatr Emerg Care 2006;22:689-99.

8 Acworth J, Babl F, Borland M, et al. Patterns of presentation to the Australian and New Zealand Paediatric Emergency Research Network. Emerg Med Australas 2009;21:59-66.

9 British Thoracic Society/Scottish Intercollegiate Guidelines Network. British Guideline on the Management of Asthma. 2012. http://www.brit-thoracic.org.uk/Portals/0/ Guidelines/AsthmaGuidelines/sign101 (accessed 2 Mar 2014).

10 National Institute for Health and Care Excellence. Quality Standard (QS25) - Asthma (including children and young people). 2013. http://guidance.nice.org.uk/QSD/27 (accessed 2 Mar 2014).
11 Papadopoulos NG, Arakawa $\mathrm{H}$, Carlsen $\mathrm{K}-\mathrm{H}$, et al. International consensus on (ICON) pediatric asthma. Allergy 2012;67:976-97.

12 Stanley RM, Teach SJ, Mann NC, et al.; for the Pediatric Emergency Care Applied Research Network. Variation in ancillary testing among pediatric asthma patients seen in emergency departments. Acad Emerg Med 2007;14:532-8.

13 Babl FE, Sheriff N, Borland M, et al. Paediatric acute asthma management in Australia and New Zealand: practice patterns in the context of clinical practice guidelines. Arch Dis Child 2008:93:307-12.

14 Scott SD, Grimshaw J, Klassen TP, et al. Understanding implementation processes of clinical pathways and clinical practice guidelines in pediatric contexts: a study protocol. Implement Sci 2011;6:133.

15 Lyttle MD, O'Sullivan R, Hartshorn $S$, et al.; on behalf of PERUKI. Pediatric Emergency Research in the UK and Ireland (PERUKI): developing a collaborative for multicentre research. Arch Dis Child 2014;99:602-3.

16 Cunningham S, Logan C, Lockerbie L, et al. Effect of an integrated care pathway on acute asthma/wheeze in children attending hospital: cluster randomized trial. J Pediatr 2008;152:315-20.

17 Griffiths B, Ducharme FM. Combined inhaled anticholinergics and short-acting beta2-agonists for initial treatment of acute asthma in children. Cochrane Database Syst Rev 2013:8:CD000060.

18 Starkey E, Mulla H, Sammons H, et al. Intravenous salbutamol for childhood asthma: evidence based medicine? Arch Dis Child 2014;99:873-7.

19 Browne GJ, Trieu L, Van Asperen P. Randomized, double-blind, placebo-controlled trial of intravenous salbutamol and nebulized ipratropium bromide in early management of severe acute asthma in children presenting to an emergency department. Crit Care Med 2002;30:448-53.

20 Shann F. Dose of intravenous infusions of terbutaline and salbutamol. Crit Care Med 2000:28:2179-80.

21 Shann F. Intravenous salbutamol. Pediatr Crit Care Med 2003;4:128.

22 Powell C, Kolamunnage-Dona R, Lowe J, et al. Magnesium sulphate in acute severe asthma in children (MAGNETIC): a randomised, placebo-controlled trial. Lancet Respir Med 2013;1:301-8.

23 Powell C, Dwan K, Milan SJ, et al. Inhaled magnesium sulfate in the treatment of acute asthma. Cochrane Database Syst Rev 2012;12:CD003898.

24 Cronin J, McCoy S, Nally S, et al. A randomised trial of dexamethasone versus prednisolone in the treatment of acute paediatric asthma exacerbations. Arch Dis Child 2012;97(Suppl 2):A109.

25 Hames H, Seabrook JA, Matsui D, et al. A palatability study of a flavored dexamethasone preparation versus prednisolone liquid in children. Can J Clin Pharmacol 2008;15:e95-8.

26 Qureshi F, Zaritsky A, Poirier MP. Comparative efficacy of oral dexamethasone versus oral prednisone in acute pediatric asthma. J Pediatr 2001;139:20-6.

27 Greenberg RA, Kerby G, Roosevelt GE. A comparison of oral dexamethasone with oral prednisone in pediatric asthma exacerbations treated in the emergency department. Clin Pediatr (Phila) 2008;47:817-23.

28 Altamimi S, Robertson G, Jastaniah W, et al. Single-dose oral dexamethasone in the emergency management of children with exacerbations of mild to moderate asthma. Pediatr Emerg Care 2006;22:786-93.

29 Keeney GE, Gray MP, Morrison AK, et al. Dexamethasone for acute asthma exacerbations in children: a meta-analysis. Pediatrics 2014;133:493-9.

30 Hartshorn S, Bevan C, Cleugh F, et al. What are the research priorities of paediatric emergency medicine clinicians in the United Kingdom and Ireland? An international survey. Arch Dis Child 2014;99(Suppl 1):A5-6.

31 Morris I, Lyttle M, Doull I, et al. What intravenous treatment is currently being administered for acute severe wheeze in childhood in emergency departments around the UK and Ireland? Arch Dis Child 2014;99(Suppl 1):A39-40. 